\title{
Freire Marreco e Eu, Um Século Depols
}

\author{
Maria Filomena Camões*
}

\author{
"A Universidade é Universal" \\ Fernando Carvalho Barreira (1928-1976)
}

\begin{abstract}
O Prémio Freire Marreco é o prémio de maior prestígio e o único que inclui uma medalha, atribuído anualmente pela Universidade de Newcastleupon-Tyne, UK, ao seu melhor aluno de Mestrado em Química, MChem. Começou por ser atribuído em 1904 e era constituído por uma medalha de bronze e livros num valor de £5; hoje em dia é bastante superior! Foi instituído em honra e memória de Algernon Freire Marreco (filho de pai português e mãe inglesa), o primeiro Professor de Química do Colégio Armstrong de Ciência de Newcastle (Figura 1), na altura da Universidade de Durham, fundado em 1871.
\end{abstract}

A existência do Prof. Algernon Freire Marreco chegou ao meu conhecimento em 1971, quando, por feliz coincidência, eu, aluna de Doutoramento recém-chegada à Universidade de Newcastle, me deparei com as celebrações do primeiro centenário da fundação do Colégio Armstrong de Ciência. Eu, que até aí, por alegadamente "ser a primeira pessoa portuguesa a chegar ali", me vinha confrontado com estranhas questões, algumas das quais dariam anedotas dignas de antologia, sobre Portugal e os hábitos dos Portugueses. Aí estava eu, jovem estudante portuguesa no estrangeiro, a colher da semente do conhecimento, que afinal tinha sido lançada, havia não tanto tempo assim, por um compatriota! Desde então empenheime em saber mais sobre este dois homens, Pai e Filho, que apesar de terem sido figuras de primeira linha na

CCMM-DQB-FCUL, C8 Campo Grande, 1749-016 LisE-mail: fcamoes@fc.ul.pt

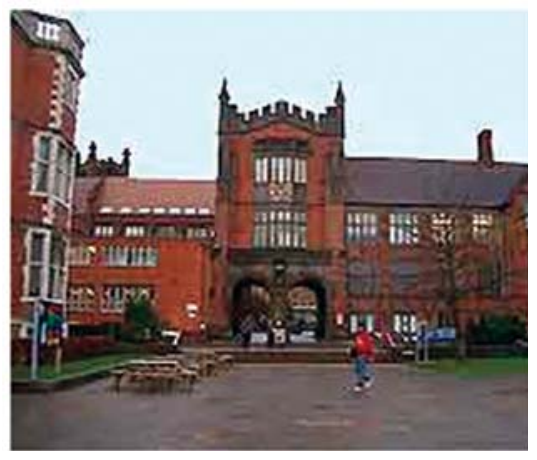

Figura 1 - Colégio Armstrong da Universidade de Newcastle-upon-Tyne, UK

divulgação da Química do século XIX na Inglaterra Vitoriana e no fomento de relações científicas com Portugal, permanecem pouco conhecidos!

Algernon Freire Marreco (1835-1882) foi o mais velho dos 11 filhos de António Joaquim Freire Marreco (17871850), um português de Penafiel, emigrado para o Brasil em 1808, juntamente com o Rei D. João VI e a Corte Portuguesa que se instalaram no Rio de Janeiro, escapando às tropas $\mathrm{Na}$ poleónicas que invadiram e tentaram subjugar Portugal. Quando, após 12 anos, em 1820, o Rei regressou a Portugal, António Joaquim Freire Marreco (o nome Marreco foi alcunha adquirida no Brasil, associada por qualquer razão, não tanto a algum defeito físico, mas a "patos marrecos"; a alcunha foi depois adoptada como sobrenome oficial), voltou também. Embora haja registos da sua permanência aqui em 1822 como sócio da nova Sociedade Promotora da Indústria Nacional, a quem terá oferecido um folheto sobre uma nova impressora de ferro inventada por George Clymer, é certa a sua presença em Londres, em 1821, associada ao comércio de vinhos, em parceria com William Harrison e o fiIho, Thomas Elliot Harrison, famoso engenheiro de comboios. O negócio prosperou e, em 1825, adquiriu uma casa a que chamou "Cintra Cottage" em Stoke-Newington, onde inclusivamente albergou Almeida Garrett, a quem arranjou trabalho e meios de subsistência em França.

António Joaquim Freire Marreco promoveu e fundou a primeira associação de químicos, no Mundo, de cujos órgãos directivos fez parte, a London Chemical Society que, apesar de ter tido vida curta, 1824-1825, lançou o primeiro jornal científico inteiramente dedicado à Química, The Chemist, 1824, 1, 197, 192, 206, 221, 237; 2, 162e, "escrita para o cidadão comum, anónimo, que quer saber notícias de Química, por exemplo acerca de Davy". A ideia foi retomada em 1841 pela Royal Society of Chemistry, que só mais tarde, se tornou também num forum académico.

O seu nome consta das listas de endereços de Londres até 1830, mas a partir daí são-lhe conhecidos vários endereços em County Durham, em Northumberland, no Nordeste de Inglaterra, onde, em associação com os Stephensons, investiu no desenvolvimento de projectos ferroviários, na exportação de carvão de Newcastleupon-Tyne para Portugal e na exploração das potencialidades da cal como reagente químico.

Durante a sua estadia em Inglaterra, António Joaquim Freire Marreco manteve ligações fortes a Portugal. Foi agraciado com a Ordem de Cristo pela Raínha de Portugal, D. Maria II, 
em 1837, foi secretário da comissão de refugiados em Londres e foi nomeado representante português em Londres da Grande Loja Maçónica do Brasil.

Após alguns anos de actividade em Inglaterra, António Joaquim Freire Marreco regressou a Portugal com a mulher, Anna Laura Harrison (17 anos mais nova, sobrinha de William Harrison, filha de John Fairweather Harrison), as duas filhas e o filho Algernon, nascido a 3 de Novembro de 1835, na casa de família na Military Road, South Shields. Os 8 filhos que tiveram posteriormente nasceram já em Portugal. Após o seu falecimento, a 19 de Agosto de 1850, com idade de 62 anos, a viúva, que lhe sobreviveu 42 anos, optou por regressar a Inglaterra com os filhos.

Algernon Freire Marreco, que tinha frequentado a escola em Portugal, continuou os estudos na famosa Collingwood Bruce School. Fascinado com a Química, foi trabalhar nos laboratórios Thomas Richardson em Portland Place, $n^{\circ} 5$, Newcastle-uponTyne e dava lições particulares a um guinéu por semana. Os trabalhos que efectuou sobre minerais, solos, águas e outros produtos levaram a que se tivesse tornado no mais famoso analista do Norte de Inglaterra, respeitado e reconhecido por clientes tais como a Companhia do Gás e os Caminhos de Ferro, que tinham começado a perceber a importância da Química para o desenvolvimento das suas actividades. Em breve se tornou Sócio de Thomas Richardson, docente de Química na Universidade de Durham e no Colégio de Medicina de Newcastle-upon-Tyne, que em 1859 o nomeou seu Assistente. Algernon sucedeu-lhe em 1867. Quatro anos mais tarde, em 1871, quando foi fundado em Newcastle-upon-Tyne, o Colégio Armstrong da Universidade de Durham, Algernon Freire Marreco foi o seu primeiro Professor de Química. Os dois Colégios fundiram-se em
1937 no King's College que integrou a Universidade de Newcastle-uponTyne aprovada oficialmente em 1963. Algernon Freire Marreco fundou a secção da Chemical Society em Newcastle-upon-Tyne, de que foi o primeiro Presidente. Fundou também o Museu Tecnológico de Newcastle-uponTyne e a primeira associação, a nível mundial, de profissionais da Ciência, o Chemistry Institute (1877).

Não são muitos os escritos do Professor A. Marreco, mas uma comunicação em que apresenta resultados de uma série de experiências sobre explosão de poeiras de carvão, publicada em Transactions of the North of England Institute of Mining and Mechanical Engineers, constitui uma das contribuições mais valiosas para a história do assunto.

Orador exímio, era linguista fluente e falava com transbordante entusiasmo e forte sentido de humor. Muito respeitado pelos seus alunos, alguém o descreveu como "um professor talhado no céu, amado por alunos e amigos, terror de malfeitores (evil-doers) em relação aos quais a sua língua foi um chicote impiedoso". Como professor, considerava que alguém nessa posição deveria dedicar-se inteiramente à missão de ensinar e defendeu o seu ideal de que a partir do dia da sua nomeação, nunca mais recebeu qualquer remuneração por trabalho não relacionado com a sua função e com o currículo das disciplinas que leccionava. Ao contrário de seu pai, Algernon era politicamente conservador, sendo no entanto defensor da emancipação da Mulher.

Algernon Freire Marreco, homem notável na sua área e em muitas coisas para além dela, morreu, em sofrimento, solteiro e sem descendência, a 27 de Fevereiro de 1882, na sua residência de Westmorland Road, Newcastleupon-Tyne. O seu funeral, para o qual, a seu pedido, não houve os tradicionais convites, foi uma das maiores e mais impressionantes manifestações de sempre, em Newcastle.

António Joaquim Freire Marreco jaz no Cemitério Inglês em Lisboa. A sua campa (Figura 2) é mantida pelo Banco Espírito Santo cuja origem remontará a uma casa de câmbio da Calçada dos Paulistas eventualmente adquirida à família de António Joaquim Freire Marreco por "José", nascido a 13 de Maio de 1850, filho de pais incógnitos, sendo dado como certo ser filho ilegítimo de Simão da Silva Ferraz de Lima e Castro, Conde de Rendufe, e de Maria Angelina Saraiva, uma mulher do povo, com quem sempre morou (e com o padrasto, o marceneiro Luís José Machado Lopes, na Travessa dos Fiéis de Deus, no Bairro Alto); tendo por padrinhos um funcionário da igreja e Nossa Senhora, adoptou, pelo Crisma, o nome José Maria do Espírito Santo e Silva (sendo que Silva é o segundo nome do Conde de Rendufe), o Patriarca da Família Espírito Santo, bisavô de Ricardo Salgado, actual administrador do Banco Espírito Santo.

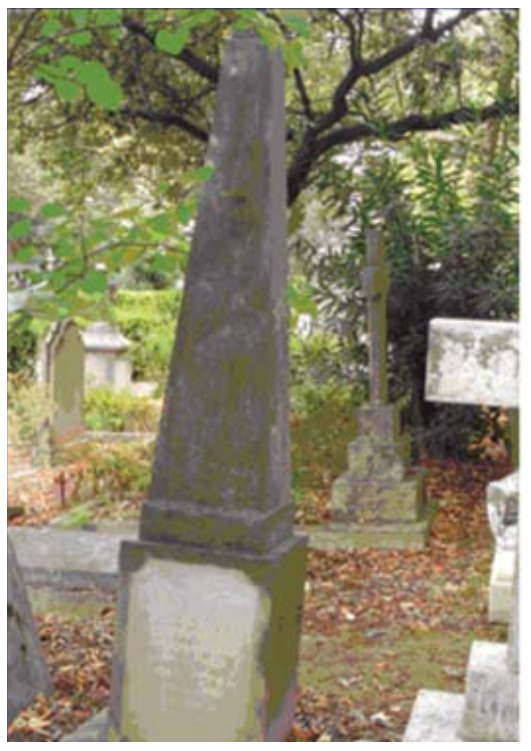

Figura 2 - Campa de António Joaquim Freire Marreco no Cemitério Inglês, em Lisboa

\section{REFERÊNCIAS}

C.A.Russell, Lit \& Phil Bicentenary Lectures, Newcastle, 1994, p.104 [capítulo 6]

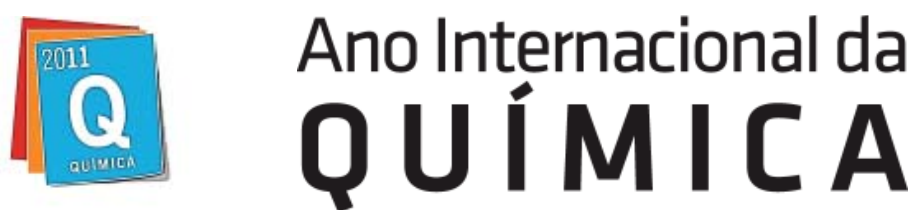

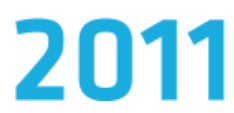

